\title{
Adapting a clinic-based HIV stigma intervention to Newark, New Jersey
}

\author{
Ann D. Bagchi, William Holzemer \\ School of Nursing, Rutgers - The State University of New Jersey, Newark, New Jersey, United States
}

Received: September 2, 2019

Accepted: October 30, 2019

Online Published: November 7, 2019

DOI: $10.5430 / \mathrm{cns} . v 8 \mathrm{n} 1 \mathrm{p} 1$

URL: https://doi.org/10.5430/cns.v8n1p1

\begin{abstract}
This study describes implementation of a clinic-based HIV stigma reduction workshop adapted from work done in Africa to an HIV clinic in Newark, New Jersey. Clinic workers and clients participated in a series of four, three-hour workshops designed to reduce HIV-related stigma. Quantitative data, including the Berger HIV Stigma Scale and the HIV Stigma and Discrimination among Health Facility Staff questionnaire, were collected pre- and post-test over a two-week period and again at 12 months. Average scores on the Berger Scale fell between baseline and the two-week follow-up, but increased above the baseline level after one year. Average scores on the facility questionnaire were low at baseline and decreased over the study period. Results suggest a need for "booster sessions" to ensure that the intervention sustains efficacy in the long-term. Furthermore, the findings from this preliminary work suggest the need for further research and a larger scale intervention using a randomized control trial design to formally test the intervention's effectiveness.
\end{abstract}

Key Words: HIV, Stigma interventions, Feasibility study, Healthcare workers, Berger Scale

\section{INTRODUCTION}

\subsection{The impact of Stigma on HIV prevention and care}

Since the earliest days of the epidemic, stigma has had a profoundly negative impact on health care access, services, and outcomes of care for people living with HIV (PLHIV). ${ }^{[1-4]}$ Stigma creates barriers to success in achieving goals along the HIV Care and Prevention Contina, with HIV-related and intersecting stigmas associated with barriers to accessing prevention and testing services, engaging and remaining in care, and adhering to treatment plans. ${ }^{[5-8]}$ Stigma is also associated with a lower overall quality of life (QoL) among PLHIV and is a significant factor driving disparities in the incidence and prevalence of HIV in the U.S. ${ }^{[9-11]}$

The original National HIV/AIDS Strategy (NHAS) called for HIV-related care and services "free from stigma and discrimination.." ${ }^{[12]}$ [p. vii] Despite a wide range of initiatives that have been designed to address HIV-associated stigma, reliable evidence of their effectiveness in reducing stigma within the United States has been lacking. ${ }^{[13-16]}$ The update to the NHAS called for multi-method approaches that can improve outcomes by addressing HIV-associated stigma through education, social media, and policy changes. ${ }^{[8]}$ Systematic reviews suggest a number of limitations to the design and implementation of prior interventions, and insufficient evidence of their efficacy. ${ }^{[13,15,17,18]}$ Many existing interventions include stigma reduction as only one component of a broader HIV educational activity and the majority do not use a validated measure of HIV-associated stigma. In addition, there have been very few studies specifically targeting

\footnotetext{
*Correspondence: Ann D. Bagchi; Email: abagchi@sn.rutgers.edu; Address: School of Nursing, Rutgers - The State University of New Jersey, Newark, New Jersey, United States.
} 
interventions towards stigma occurring in healthcare settings.

\subsection{Building on a prior clinic-based intervention}

The present study presents preliminary work to address many of the limitations of prior research. It drew on a clinic-based intervention tested across five African countries, which used a case study approach to address two common sources of stigma: healthcare providers and the community. ${ }^{[19]}$ The original study recruited 10 nurses and 10 PLHIV from one health clinic in each country to participate in a two-day workshop designed to increase awareness and understanding of HIV-related stigma and to develop a project that could be implemented and evaluated within the site or the community to reduce stigma. Workshops were led by co-facilitators, a nurse from the clinic and a consumer living with HIV who was active in support groups in the area. Data collected for the study included: (1) an intervention report written by the workshop facilitators, (2) standardized pretest/posttest questionnaires, and (3) interviews with clinic opinion leaders. The study examined the effects of workshop participation on perceptions of stigma and the types of stigma reduction projects undertaken in each site, along with their perceived outcomes. The study found that workshop participation was associated with a decrease in reported stigma and an increase in self-esteem among PLHIV and an increase in HIV testing among participating nurses. Furthermore, participants and opinion leaders at the sites reported positive effects on understanding and awareness of HIV-related stigma as a result of the stigma reduction projects. ${ }^{[19]}$

\subsection{Study adaptations}

The primary goal of the present study was to test the feasibility of a similar clinic-based stigma reduction workshop within a population at the epicenter of the U.S.'s HIV epidemic. Thus, the primary goal of the present study was to determine whether a similar clinic-based stigma reduction workshop could be implemented in the United States. As such, we sought to test the format, procedures, and outcomes of a similar set of clinic-based workshops in Newark, New Jersey. A secondary goal was to identify which components of the intervention would need to be adapted to facilitate scale-up for purposes of a random assignment study. Finally, we sought to determine the long-term effects of the intervention by examining outcomes after one year.

In adapting the workshops to the U.S. context, we made several changes to the study's design and implementation. First, we adjusted the workshop topics from the original study to address the HIV epidemic in the U.S. and the local context, for example, including discussion of the NHAS, cultural competency, and intersecting stigmas (see Table 1 for a comparison of topics covered in the sessions for the two studies). Second, because our original plan was to replicate the workshops in healthcare settings throughout the state, we chose to have a single facilitator (the primary author, a nurse) lead the workshops to decrease variability in implementation. Third, we did not limit our study to nurses, instead allowing participation by any staff member with consumer contact. We also used a different set of data collection instruments than the original study (e.g., replacing the HIV/AIDS Stigma Instrument-Nurse with the Comprehensive Questionnaire on HIV Stigma and Discrimination among Health Facility Staff ${ }^{[20,21]}$ to address the professional backgrounds of staff participants and to capture issues such as cultural competency at the clinic and health literacy of participants. Because the facilitator was also a member of the study team, we did not include a formal implementation report as a data source, relying instead on the facilitator's input to the analysis and writeup of study findings. Rather than interview clinic leaders, we used findings from the workshops themselves and from open-ended questions in workshop evaluations to assess the intervention's effects. Finally, the purpose of this study was to examine the feasibility of replicating the workshops; therefore, our analysis focused on the outcomes of the workshops and did not address the specifics of the community-based project undertaken by our study's participants.

\section{Methodology}

There are more than 37,000 PLHIV in New Jersey. ${ }^{[22]}$ Within the greater Newark area, prevalence rates in some sub-groups are as high as those seen in sub-Saharan African countries. ${ }^{[23]}$ To date, there have been no studies assessing the extent and character of HIV-related stigma in the Newark area and no formal studies of interventions to address it. As the community with the highest prevalence rates in the state, Newark represents an ideal location for the design and testing of HIV stigma interventions and served as the setting for our study.

\subsection{Site selection and participant recruitment}

The study brought together five staff members and eight consumers from an HIV clinic in Newark (chosen based on convenience and prior collaborations with the study team) in four three-hour workshops conducted over a two-week timeframe. Workshop activities included full group discussions, brainstorming, card storming (i.e., eliciting short responses to a trigger question and then working as a team to sort ideas into common themes), and small group work.

Clinic leaders recruited staff members with direct consumer contact based on their interest and willingness to participate in after hour activities. Consumer participants had to be 18 or older, living with HIV, and able to participate in group 
discussions. Consumers were recruited through flyers posted in prominent locations throughout the facility and through word of mouth during program activities. Participants received dinner because the workshop meetings were held in the evening and $\$ 25$ Visa gift cards as incentive payments for each questionnaire completed (for a total of up to \$75). The research protocol for the study was approved by the Rutgers University institutional review board (IRB), as well as the clinic's IRB.

Table 1. Comparison of workshop topics by session: Original versus adapted study

\begin{tabular}{cll}
\hline Session & African Study Topic $^{*}$ & New Jersey Study Topic \\
\hline 1 & What is HIV/AIDS stigma? Understanding and defining stigma & Review of National HIV/AIDS Strategy \\
2 & The outcomes of stigma & What is HIV/AIDS stigma? Understanding and defining stigma \\
3 & Coping with stigma & Outcomes of stigma \\
4 & Why is stigma hard to change? & Review of findings from baseline data collection \\
5 & Identifying stigma interventions and local examples & Cultural competency and HIV/AIDS \\
6 & Evaluating options for action & Coping with stigma \\
7 & Planning for change & Why is stigma hard to change? \\
8 & Choosing project options & Types of stigma interventions and designing an intervention \\
9 & Planning the project & Planning the project \\
10 & Vision, aim, and objectives & Task analysis and the project team \\
11 & Task analysis and action plan & Evaluating the workshop experience \\
\hline
\end{tabular}

Note. ${ }^{*}$ As described in Uys et al. ${ }^{[19]}$

\subsection{Data collection}

Although the study collected data from participants using a number of standardized and previously validated survey instruments, (details provided upon request), the primary focus was on outcomes related to standardized stigma scales, namely, the HIV Stigma Scale (Berger Scale) ${ }^{[24-27]}$ for consumers and the Comprehensive Questionnaire on HIV Stigma and Discrimination among Health Facility Staff (hereafter referred to as the Facility Scale) for clinic workers. ${ }^{[21]}$ Participants also completed a workshop evaluation survey, which included space for open-ended responses. Participants completed the questionnaires prior to the first session, at the end of the final session, and again one year later. The primary author and a research assistant oversaw data collection activities, including completion of the surveys and taking notes on workshop findings. There were no audio recordings of workshop activities and no formal qualitative analysis; therefore, any qualitative findings were limited to general conclusions and short responses to open-ended questions on the survey questionnaires.

\subsection{Statistical analyses}

Given the small size of this pilot study, our analyses focused on responses to the Berger Scale and the Facility Scale and their associated sub-scales. Group means were based on the number of completed responses we were able to collect in each round. We used the non-parametric Kruskall-Wallis statistic to test for significant between-group changes in mea- sures over time and used repeated measures ANOVA to test for within-group effects for individual participants. Statistical analyses were completed using SPSS Version 23. ${ }^{[28]}$

Table 2. Consumer characteristics at baseline

\begin{tabular}{lcccc}
\hline Consumers & N = 8 & Std. Dev. & Range & \% \\
\hline Mean Age & 48.6 & 10.3 & $33-66$ & \\
Gender & & & & \\
$\quad$ Men & 7 & & & 87.5 \\
$\quad$ Women & 1 & & & 12.5 \\
Race/Ethnicity & & & & \\
$\quad$ African American & 8 & & & 100.0 \\
Highest Degree & & & & \\
$\quad$ Less than High School & 6 & & & 75.0 \\
2 Year College & 1 & & & 12.5 \\
$\quad$ College Degree & 1 & & & 12.5 \\
\hline
\end{tabular}

\section{RESUlts}

\subsection{Consumers}

Although eight consumers participated in the workshops, only six provided data at all three points of data collection. All of the consumer participants were African American, with an average age of 48.6 years $(S D=10.3)$, most were men, and the group overall had low educational background and income (see Table 2). Overall, consumer ratings of their stigma experiences fell between the first and the final session of the workshops, but increased again at the one-year 
follow-up. Average scores were around the middle of the range across each sub-scale and for the total score prior to the first workshop session (see Table 3). By the end of the foursession series, mean scores on the sub-scales had dropped an average of four points. The total average Berger Scale Score dropped by 6.9 points, from 93.2 to 86.3 . Over the longterm, the apparent positive effects of the workshops were not maintained and, in fact, scores increased from baseline to one-year follow-up.

Analyses of changes over time in the Berger Scale (i.e., total score and sub-scales) using the Kruskal-Wallis test did not reveal any significant differences. However, a repeated measures ANOVA to test for significant change over time within participants found a significant change in the Personalized Stigma sub-scale $(F[7]=4.306, p=.045)$. Further analyses using paired sample $t$-tests revealed that the effect was due to a significant increase in scores for this sub-scale from the two-week to one-year follow-up $(t[7]=-3.127, p=.020)$, with one consumer's score increasing by 32 points over these two time periods.

Table 3. Average consumer scores on Berger HIV Stigma Scale

\begin{tabular}{|c|c|c|c|c|c|c|c|c|c|c|}
\hline \multirow{2}{*}{ Scale/Sub-scale } & \multirow{2}{*}{$\begin{array}{l}\text { Scale } \\
\text { Range }\end{array}$} & \multicolumn{3}{|c|}{ Baseline $(\mathrm{N}=7)$} & \multicolumn{3}{|c|}{ Two Weeks $(\mathbf{N}=8)$} & \multicolumn{3}{|c|}{ One Year $(N=7)$} \\
\hline & & $M$ & Std. Dev. & Range & $M$ & Std. Dev. & Range & $M$ & Std. Dev. & Range \\
\hline Personalized Stigma & $18-72$ & 36.7 & 11.9 & $21-61$ & 33.2 & 14.1 & $21-61$ & 42.7 & 9.9 & $35-58$ \\
\hline Disclosure Concerns & $10-40$ & 27.2 & 5.1 & $21-35$ & 26.2 & 4.7 & $17-31$ & 27.0 & 4.3 & $21-34$ \\
\hline Negative Self-image & $13-52$ & 29.7 & 8.7 & $18-41$ & 27.0 & 8.7 & $17-43$ & 28.8 & 6.8 & $22-42$ \\
\hline Total Berger Score & $40-160$ & 93.2 & 19.8 & $64-122$ & 86.3 & 23.0 & $55-126$ & 96.4 & 20.9 & $78-135$ \\
\hline
\end{tabular}

Table 4. Staff characteristics at baseline

\begin{tabular}{|c|c|c|c|c|}
\hline Variables & $\mathbf{N}=\mathbf{5}$ & Std. Dev. & Range & $\%$ \\
\hline Mean Age & 50.0 & 3.46 & $47-56$ & \\
\hline \multicolumn{5}{|l|}{ Gender } \\
\hline Men & 2 & & & 40 \\
\hline Women & 3 & & & 60 \\
\hline \multicolumn{5}{|l|}{ Race/Ethnicity } \\
\hline African American & 4 & & & 80 \\
\hline Caucasian & 1 & & & 20 \\
\hline \multicolumn{5}{|l|}{ Current Job } \\
\hline Health Educator & 1 & & & 20 \\
\hline Nurse & 1 & & & 20 \\
\hline Project Manager & 3 & & & 60 \\
\hline
\end{tabular}

\subsection{Staff members}

Four of the five staff participants were African American, the other was Caucasian, with an overall mean age of 50 years $(S D=3.5)$ (see Table 4). One was working as a nurse at the clinic, another was a health educator, and the others were project managers. Overall, scores on the Facility Survey were low, with the average baseline scores only two to four points above the minimum value on the sub-scales (see Table 5). Total facility score was 57.4 at baseline $(S D=4.5)$, which is in the bottom quartile of the score's range. Analyses using the Kruskal-Wallis test revealed significant decreases over time in the Facility Environment $\left(\chi^{2}[4]=10.47, p=.033\right)$ and Opinion of PLHIV $\left(\chi^{2}[4]=10.05, p=.040\right)$ sub-scales and in the total score $\left(\chi^{2}[4]=9.70, p=.046\right)$. There were no significant differences within staff participants in their scores on any of the scale items.

Table 5. Average clinic worker scores on facility survey

\begin{tabular}{|c|c|c|c|c|c|c|c|c|c|c|}
\hline \multirow{2}{*}{ Scale/Sub-scale } & \multirow{2}{*}{$\begin{array}{l}\text { Scale } \\
\text { Range }\end{array}$} & \multicolumn{3}{|c|}{ Baseline $(\mathbf{N}=5)$} & \multicolumn{3}{|c|}{ Two Weeks $(\mathbf{N}=5)$} & \multicolumn{3}{|c|}{ One Year $(N=5)$} \\
\hline & & $M$ & Std. Dev. & Range & $M$ & Std. Dev. & Range & $M$ & Std. Dev. & Range \\
\hline Infection Control & $8-32$ & 10.6 & 2.1 & $8-13$ & 9.2 & 1.3 & $8-11$ & 9.6 & 1.1 & 8-11 \\
\hline Facility Environment & $7-28$ & 11.4 & 2.6 & $10-16$ & 10.4 & 0.9 & $10-12$ & 10.6 & 0.9 & $10-12$ \\
\hline Facility Policy & $5-20$ & 15.0 & 1.4 & $14-17$ & 15.6 & 1.5 & 14-17 & 14.2 & 1.6 & $13-17$ \\
\hline Total Facility Score & $36-144$ & 57.4 & 4.5 & $52-63$ & 55.6 & 5.4 & $49-64$ & 53.8 & 2.7 & $50-56$ \\
\hline
\end{tabular}




\subsection{Qualitative study findings}

Participants were actively engaged in each session, with all participating in every activity and contributing to group discussions. All of the participants reported greater feelings of empowerment, responsibility, energy, and influence following the four sessions. One of the things that participants liked best was that the workshops included positive interactions between clients and staff, with four participants stating specifically that this was the best part of the intervention. Another key finding was the recognition that all of the participants experience stigma "in one form or another" and have their own stigmas toward members of other groups (i.e., not necessarily toward PLHIV or their service providers).

\subsection{Findings on workshop content}

There were five notable findings regarding the content of the sessions. First, the baseline workshop session included discussion of the NHAS. None of the participants (including clinic staff) were previously aware of its existence but expressed satisfaction with the fact that HIV and its related stigma are national priorities. Second, a discussion of the outcomes of stigma focused on the negative consequences (e.g., shame, failure to adhere to medications), but when posed the question whether there are any positive aspects of HIV-related stigma, one participant said that, "Being able to testify to my experience and prevent others, especially young people, from making the same mistakes - that's a positive." Third, clients expressed satisfaction with the ability to review the findings from the baseline questionnaires. They found the exercise valuable and expressed interest in the fact that the highest scores on the Berger scale items related to disclosure. Fourth, although the clinic workers were well aware of the concept of cultural competency and said that they incorporate these principles in their work at the clinic, the concept was new to the client participants. They were interested in seeing more information about cultural competency throughout the clinic (e.g., a patients' bill of rights). Finally, participants enjoyed the interactive nature of the card storming activity to identify reasons that HIV-related stigma is so intractable. They identified the following categories of reasons: discrimination, mental health issues, beliefs, geography, acceptance, fear, and ignorance, but all agreed that lack of information and ignorance about HIV and its means of transmission are the most significant factors perpetuating HIV-associated stigma.

\subsection{Findings related to processes and procedures}

Based on our experience conducting the pilot study, there were a number of things that may need to be reconsidered for a larger scale study. First, the pilot study comprised four sessions of three hours with no structured breaks built into the schedule, but participants were free to take breaks as needed. This structure allowed for a continual flow of the workshop material and avoided delays in bringing participants back to task after a structured work break. However, this approach could create fatigue for some participants. Second, during the first session, the participants completed the questionnaires while they ate their dinner. This created delays in completing the surveys and starting the session on time. Similarly, the process of incentive payment took time away at the end of the session. The food and gift cards were important and successful incentives for participation, but the timing of these tasks may need to be adjusted to ensure sufficient time for intervention activities. Third, although the original model called for two moderators, we found that the sessions worked well with the single moderator, with participants giving a high rating of the moderator's effectiveness ( 4.8 on a scale ranging from one [strongly disagree that the moderator was effective] to five [strongly agree]). Finally, it was useful to partner with the clinic staff to oversee client recruitment due to the efficiency and ability to protect clients' privacy.

\subsection{Findings related to the community project}

Participants initially identified four options for the clinic or community-based project: (1) a health fair, (2) a dramatic performance addressing HIV and its related stigma, (3) one-on-one counseling between an HIV-positive client and recently diagnosed individual, and (4) a community forum related to HIV-related stigma. During the final session, the participants voted on conducting a health fair, to be held in a local city park. They formed teams to address planning, volunteers, vendors (e.g., food, crafts, and activities), health services, HIV testing, funding, and setup/clean up. All of the activities were to be centered on HIV and stigma reduction, with the possibility of incorporating some of the other ideas from the workshop (e.g., the dramatic performance) into the event. At the one-year follow-up, staff noted that they held the health fair as planned, but did not track outcomes specific to the effects on HIV-associated stigma.

\section{Discussion}

The results of this feasibility study suggest that it is possible to adapt the HIV stigma reduction workshops of Uys et al. ${ }^{[19]}$ to the clinical care setting in the United States. Because the goals and instruments of this study were different from those of the original study, results are not directly comparable. For example, while Uys et al. ${ }^{[19]}$ used the HIV/AIDS Stigma Instruments to assess stigma outcomes, our study relied on the Berger scale. ${ }^{[20,24]}$ However, both studies documented some positive effects on stigma awareness and understanding among participants. 


\subsection{Study findings}

Although based on a small sample size, this pilot study found that the workshops were associated with decreases in some sub-scales of the Berger Stigma Scale and the Facility Survey, but that these decreases did not persist among consumers at one-year follow-up, and actually increased. Future research should examine the robustness of these findings using a larger sample size and explore the reasons for the increase. It may be that participation in the workshops heightened consumers' awareness of stigma and its effects such that they were more likely to notice stigmatizing and discriminating behavior. Ensuring long-term reductions in stigma may require regular intervention "boosters" to enhance feelings of self-efficacy.

Based on the facility survey sub-scales, the study did not clearly support effectiveness of the workshops in reducing stigma among clinic workers. In this sample, clinic workers had received training on stigma and discrimination, reported working regularly with PLHIV, and had low facility-level stigma scores from the outset. However, the decrease in total facility score between baseline and one-year follow-up suggests that the intervention may have had some positive effects. Future research should examine the effects of the workshops in settings that do not specialize in HIV care or that do not regularly see as many PLHIV.

With respect to the processes and procedures followed, the pilot study suggests some areas for change. First, it may be necessary to revise the timing and schedule of the workshop sessions. Participants in the pilot study found it most convenient to meet toward the end of the workday and over the dinner hour. However, these participants lived either within close proximity to the clinic or had access to personal or public transportation to facilitate their participation. With a goal of implementing the workshops in a wider range of geographic and clinical settings, it may be necessary to adjust workshop timing and setting to accommodate the needs of participants. Second, to minimize disruptions and facilitate data collection, it may be necessary to set aside a separate room in which participants could complete questionnaires before starting the planned activities. It would also be helpful to provide extra time in the first and final session for data completion and incentive payment. Finally, as noted previously, the model of a single, clinically-trained moderator worked well in the pilot study. However, to adhere more closely to the original model and to stay true to the call for greater participation of PLHIV, ${ }^{[29]}$ future implementation should employ a clinically-trained moderator living with HIV.

In terms of planning for the clinic-/community-level project, there should be greater standardization to ensure that projects are implemented and that their effects on HIV-associated stigma are evaluated. As the activity is currently organized, workshop participants have significant leeway in the selection and design of stigma-reduction projects. While there must be some leniency to ensure that the projects address the goals of participants and the needs of the local context, some structure may be necessary to be able to assess the projects' effects and ensure some level of comparability across sites (including a formal plan for implementation and evaluation). Such structure could be achieved by asking participants to focus on a particular type of stigma-related outcome (e.g., failure to remain engaged in care), mechanism or activity (e.g., social media campaign), or type of stigma (e.g., disclosure concerns).

A major emphasis of the 2020 update to the NHAS is on outcomes along the HIV Care Continuum. ${ }^{[8]}$ McNairy and El-Sadr ${ }^{[6]}$ have also emphasized the importance of the HIV Prevention Continuum. Because the workshops took place before publication of these documents, the Continua were not a specific focus of the workshops. However, research is currently underway to revise the model based, in part, on the results of this initial work. The revised approach will include a discussion of the HIV Care and Prevention Continua as a topic and will identify potential projects that workshop participants could undertake to improve outcomes along the Continua by addressing sources of stigma at each stage.

\subsection{Implications for practice}

Based on responses from the workshop evaluations, participants enjoyed the opportunity to work together to learn and share perspectives on HIV-related stigma. Although the findings are suggestive at best, it may be beneficial for clinics to implement regular workgroup meetings between clinic workers and consumers to discuss issues related to HIV-associated stigma and strategize quality improvement activities designed to address these specific problems. This may help to maintain and sustain stigma reduction over the long-term. In this context, collecting and sharing aggregated, facility-level data may help consumers feel more engaged in the process and able to identify specific targets for stigmareduction activities. This would also support UNAIDS's goal for greater participation of PLHIV in HIV-related research and activities. ${ }^{[29]}$

In addition, in light of the success of biomedical interventions (i.e., regular and consistent use of antiretroviral medications), efforts to promote the use of pre-exposure prophylaxis (PrEP) and awareness of the elimination of HIV transmission through achievement of an undetectable viral load (i.e., Undetectable $=$ Untransmittable) will be more effective when coupled with stigma reduction interventions 
targeting those living with HIV, as well as those at-risk. ${ }^{[30,31]}$ Current research building from this feasibility study is examining ways to enhance participation among nurses and other healthcare workers, as well as among members of the broader community (e.g., friends and family members of PLHIV and those at-risk for infection). Incorporation of stigma reduction workshops into regular clinical activities (e.g., support groups, group clinical visits) could facilitate greater awareness of HIV as a chronic health condition and improve outcomes along both Continua.

Based on the discussions that took place, clinics may also benefit by providing more information about cultural competency and the goals of the NHAS related to HIV-associated stigma. Consumers did not report significant problems with cultural competency at the clinic, but had never heard of the term. Similarly, consumers, and even staff, were unaware of the NHAS and the broader goals for stigma reduction. Greater awareness of these issues could contribute to a greater sense of self-efficacy and might encourage greater involvement in stigma-reduction initiatives among consumers living with HIV.

\subsection{Limitations}

The most significant limitations of the study were its small sample at a single HIV clinic and the lack of a control group for comparison. Although the clinic and its participants are reflective of the larger HIV epidemic in New Jersey in terms of the geographic setting and groups affected, a goal for future research will be to refine the methods and develop a larger-scale test of the workshops as an intervention tool. This will include recruiting an array of clinical sites from a wider variety of geographic settings and including a broader cross-section of participants, as discussed above. Ideally, the larger study will employ a randomized control trial using standardized procedures and tools.

Another limitation was the lack of more descriptive data regarding some of the quantitative findings. For example, based on the workshop evaluation survey, 12 of 13 subjects said that participating in the workshops affected changes in the clinic (i.e., "a little" or "a lot"). However, we did not collect qualitative data from participants regarding the types of changes they perceived. Understanding the types of changes that occur and how those changes come about will be important for assessing the specific mechanisms of the intervention's effects. As we refine the model for future implementation, we will include a more formalized method of qualitative data collection that can capture some of these effects and outcomes.

\section{CONFlicts OF INTEREST Disclosure}

The authors declare they have no conflicts of interest.

\section{REFERENCES}

[1] Golub SA, Gamarel KE. The impact of anticipated HIV stigma on delays in HIV testing behaviors: findings from a community-based sample of men who have sex with men and transgender women in New York City. AIDS Patient Care and STDs. 2013; 27(11): 621-7. PMid: 24138486. https://doi.org/10.1089/apc. 2013.0245

[2] Hatzenbuehler ML, Phelan JC, Link BG. Stigma as a fundamental cause of population health inequalities. American Journal of Public Health. 2013; 103(5): 813-21. PMid: 23488505. https: //doi.org/10.2105/AJPH. 2012.301069

[3] Katz IT, Ryu AE, Onuegbu AG, et al. Impact of HIV-related stigma on treatment adherence: systematic review and meta-synthesis. Journal of the International AIDS Society. 2013; 16(3 Suppl 2): 18640. PMid: 24242258. https://doi.org/10.7448/IAS.16.3.18640

[4] Fuster-Ruizdeapodaca MJ, Molero F, Holgado FP, et al. Enacted and internalized stigma and quality of life among people with HIV: the role of group identity. Quality of Life Research. 2014; 23(7): 196775. PMid: 24585185 . https://doi .org/10.1007/s11136-014 -0653-4

[5] Logie CH, James L, Tharao W, et al. HIV, gender, race, sexual orientation, and sex work: a qualitative study of intersectional stigma experienced by HIV-positive women in Ontario, Canada. PLoS Medicine. 2011; 8(11): e1001124. PMid: 22131907. https : //doi.org/10.1371/journal.pmed.1001124
[6] McNairy ML, El-Sadr WM. A paradigm shift: focus on the HIV prevention continuum. Clinical Infectious Diseases. 2014; 59(Suppl 1): S12-5. PMid: 24926026. https://doi.org/10.1093/cid/ ciu251

[7] Mugavero MJ, Amico KR, Horn T, et al. The state of engagement in HIV care in the United States: from cascade to continuum of control. Clinical Infections Diseases. 2013; 57: 1164-7. PMid: 23797289. https://doi.org/10.1093/cid/cit420ht tps://doi.org/10.1093/cid/cit420

[8] Office of National AIDS Policy. National HIV/AIDS Strategy: Updated to 2020. Washington, D.C.: The White House Office of National AIDS Policy; 2015.

[9] Holzemer WL, Human S, Arudo J, et al. Exploring HIV stigma and quality of life for persons living with HIV infection. Journal of the Association of Nurses in AIDS Care. 2009; 20(3): 161-8. PMid: 19427593. https://doi.org/10.1016/j.jana.2009.02.002

[10] Greeff M, Uys LR, Wantland D, et al. Perceived HIV stigma and life satisfaction among persons living with HIV infection in five African countries: a longitudinal study. International Journal of Nursing Studies. 2012; 47(4): 475-86. PMid: 19854440. https : //doi.org/10.1016/j.ijnurstu.2009.09.008

[11] Earnshaw VA, Bogart LM, Dovidio JF, et al. Stigma and racial/ethnic HIV disparities: moving toward resilience. American Psychologist 2013; 68(4): 225-36. PMid: 23688090. https ://doi.org/10.1 $037 / \mathrm{a} 0032705$ 
[12] Office of National AIDS Policy. National HIV/AIDS strategy for the United States. Washington, D.C.: The White House Office of National AIDS Policy; 2010.

[13] Brown L, Macintyre K, Trujillo L. Interventions to reduce HIV/AIDS stigma: what have we learned? AIDS Education \& Prevention. 2003; 15(1): 49-69. PMid: 12627743. https://doi.org/10.1521/ae ap.15.1.49.23844

[14] Aggleton P, Yankah E, Crewe M. Education and HIV/AIDS-30 years on. AIDS Education and Prevention. 2011; 23(6): 495-507. PMid: 22201234. https://doi.org/10.1521/aeap.2011.23.6.495

[15] Stangl AL, Lloyd JK, Brady LM, et al. A systematic review of interventions to reduce HIV-related stigma and discrimination from 2002 to 2013: how far have we come? Journal of the International AIDS Society. 2013; 16(3 Suppl 2): 18734. PMid: 24242268. https://doi.org/10.7448/IAS.16.3.18734

[16] Cook E, Purdie-Vaughns V, Meyer IH, et al. Intervening within and across levels: a multilevel approach to stigma and public health Social Science \& Medicine. 2014; 103: 101-9. PMid: 24513229. https://doi.org/10.1016/j.socscimed.2013.09.023

[17] Mahajan AP, Sayles JN, Patel VA, et al. Stigma in the HIV/AIDS epidemic: a review of the literature and recommendations for the way forward. AIDS. 2008; 22(Suppl 2): S67-79. PMid: 18641472. http s://doi.org/10.1097/01.aids.0000327438.13291.62

[18] Sengupta S, Banks B, Jonas D, et al. HIV interventions to reduce HIV/AIDS stigma: a systematic review. AIDS Behavior. 2011; 15(6) 1075-87. PMid: 21088989. https://doi.org/10.1007/s10461 $-010-9847-0$

[19] Uys L, Chirwa M, Kohi T, et al. Evaluation of a health settingbased stigma intervention in five African countries. AIDS Patient Care STDS. 2009; 23(12): 1059-66. PMid: 20025515. https: //doi.org/10.1089/apc.2009.0085

[20] Uys LR, Holzemer WL, Chirwa ML, et al. The development and validation of the HIV/AIDS Stigma Instrument - Nurse (HASIN). AIDS Care. 2009; 21(2): 150-9. PMid: 19229683. https: //doi.org/10.1080/09540120801982889

[21] Health Policy Project. Measuring HIV stigma and discrimination among health facility staff: Comprehensive questionnaire. Washington, D.C.: Futures Group, Health Policy Project; 2013.
[22] State of New Jersey. County and municipal HIV/AIDS statistics. 2018. Available from: https://www.state.nj.us/health/hiv stdtb/hiv-aids/statmap.shtml

[23] Birger RB, Hallett TB, Sinha A, et al. Modeling the impact of interventions along the HIV Continuum of Care in Newark, New Jersey. Clinical Infectious Diseases. 2014; 58(2): 274-84. PMid: 24140971. https://doi.org/10.1093/cid/cit687

[24] Berger BE, Ferrans CE, Lashley FR. Measuring stigma in people with HIV: psychometric assessment of the HIV stigma scale. Research in Nursing \& Health. 2001; 24(6): 518-29. PMid: 11746080 https://doi.org/10.1002/nur.10011

[25] Franke MF, Muñoz M, Finnegan K, et al. Validation and abbreviation of an HIV stigma scale in an adult Spanish-speaking population in urban Peru. AIDS Behavior. 2010; 14(1): 189-99. PMid: 18841460. https ://doi.org/10.1007/s10461-008-9474-1

[26] Jeyaseelan L, Kumar S, Mohanraj R, et al. Assessing HIV/AIDS stigma in south India: validation and abridgement of the Berger HIV Stigma scale. AIDS Behavior. 2013; 17(1): 434-43. PMid: 22246514. https://doi.org/10.1007/s10461-011-0128-3

[27] Li MJ, Murray JK, Suwanteerangkul J, et al. Stigma, social support, and treatment adherence among HIV-positive patients in Chiang Mai, Thailand. AIDS Education and Prevention. 2014; 26(5): 47183. PMid: 25299810. https://doi.org/10.1521/aeap. 2014. 26.5 .471

[28] IBM Corporation. IBM SPSS statistics 23. Armonk, NY: IBM Corporation; 2016.

[29] UNAIDS. The greater involvement of people living with HIV (GIPA) Available from: http://data. unaids .org/pub/BriefingNote /2007/jc1299_policy_brief_gipa.pdf

[30] Centers for Disease Control and Prevention. PrEP. 2019 August 6. Available from: https://www.cdc.gov/hiv/basics/prep.ht $\mathrm{ml}$

[31] Centers for Disease Control and Prevention. HIV treatment as prevention. 2019 August 29. Available from: https ://www. cdc.gov/ hiv/risk/art/index.html 